eISSN 2444-7986

DOI: https://doi.org/10.14201/orl201782.14827

Artículo de revisión

\title{
RESONANCIA MAGNÉTICA EN EL DIAGNÓSTICO Y SEGUIMIENTO DE LA PATOLOGÍA NASOSINUSAL
}

\author{
Magnetic Resonance Imaging in the diagnosis and monitoring of sinonasal \\ pathology
}

\begin{abstract}
Rodrigo BLANCO-HERNÁNDEZ; Ignacio MARTÍN-GARCÍA; Roberto Domingo TABERNERORICO; Miguel GONZALO-DOMÍNGUEZ; Cristina HERNÁNDEZ-RODRÍGUEZ; Manuel Ángel MARTÍN-PÉREZ
\end{abstract}

Complejo Asistencial de Zamora. Servicio de Radiodiagnóstico. Zamora. España.

Correspondencia: rblancoh@correosaludcastillayleon.es

Fecha de recepción: 23 de junio de 2016

Fecha de aceptación: 17 de agosto de 2016

Fecha de publicación: 19 de agosto de 2016

Fecha de publicación del fascículo: 1 de junio de 2017

Conflicto de intereses: Los autores declaran no tener conflictos de intereses

Imágenes: Los autores declaran haber obtenido las imágenes con el permiso de los pacientes

Política de derechos y autoarchivo: se permite el autoarchivo de la versión post-print (SHERPA/RoMEO)

Licencia CC BY-NC-ND. Licencia Creative Commons Atribución-NoComercial-SinDerivar 4.0 Internacional

(C) Universidad de Salamanca. Su comercialización está sujeta al permiso del editor

RESUMEN Introducción y objetivo: La resonancia magnética (RM) no se utiliza habitualmente como primera técnica en el estudio de las patologías nasosinusales, sino que suele ser complementaria a la tomografía computarizada (TC), sin embargo, resulta muy útil para la valoración de algunas patología y respuesta al tratamiento. Método: Se realiza una revisión bibliográfica actualizada y un estudio de los protocolos y casos más representativos que hemos realizado en nuestro centro durante los últimos 5 años Resultados: Se exponen las principales ventajas y utilidades de la RM en el diagnóstico y seguimiento de la patología nasosinusal. Se repasa la anatomía de los senos paranasales y fosas nasales a través de imágenes de RM en los tres planos del espacio, se analizan las secuencias de RM empleadas, se muestran las indicaciones de las pruebas de imagen según la patología y se explican los hallazgos en RM de la patología nasosinusal, tanto inflamatoria como tumoral. Conclusiones: Si bien la RM está por detrás de la TC en cuanto opciones de diagnóstico por imagen en el estudio de la patología nasosinusal, resulta especialmente útil para la valoración de patología tumoral dada su capacidad para distinguir entre diferentes tejidos y facilitar de esta manera el diagnóstico de extensión local del tumor. Además, la RM suele ser la técnica de elección para la valoración postratamiento.

PALABRAS CLAVE diagnóstico por imagen; radiología, resonancia magnética; rinitis; sinusitis; neoplasias de senos paranasales

SUMMARY

Introduction and objective: Magnetic resonance imaging (MRI) is not commonly used as the first technique in the study of sinonasal pathology, it is usually complementary to computed tomography (CT), however it is useful for the assessment of some pathology and response to treatment. Method: Updated review and study of the protocols and the most representative 
cases carried out in our department during the last 5 years. Results: The main advantages and utilities of MRI in the diagnosis and monitoring of disease sinonasal are explained. The anatomy of the sinuses and nasal cavity through MRI in different planes is explicated. MRI sequences employed are analyzed, the indications of diagnostic imaging technique are shown according to the pathology and the imaging features in MRI are explained for both, inflammatory pathology and paranasal neoplasms. Conclusions: Although MRI is behind the TC in the study of sinonasal pathology is particularly useful for assessing tumor pathology because of its ability to distinguish between different tissues and facilitate the diagnosis extension of neoplasms. In addition, MRI is usually the technique of choice for the post-treatment evaluation.

KEYWORDS

diagnostic imaging; radiology; magnetic resonance imaging; rhinitis; sinusitis, paranasal sinus neoplasms

\section{INTRODUCCIÓN}

La resonancia magnética $(\mathrm{RM})$ no se utiliza habitualmente como primera técnica en el estudio de la patología nasosinusal, sino que suele ser complementaria a la tomografía computarizada (TC). La mayor ventaja de esta técnica es su capacidad discriminativa entre los diferentes tejidos blandos, lo que permite diferenciar un tumor de secreciones retenidas, determinar el grado de extensión tumoral (principalmente la afectación intracraneal y orbitaria), y la existencia de diseminación perineural. El mayor inconveniente, sin considerar su alto coste y escasa disponibilidad, es que es incapaz de discriminar de forma adecuada la interfase tejido-aire $y$, por lo tanto, es inadecuada para realizar el mapa prequirúrgico y para identificar engrosamientos sutiles de la mucosa [1]. Además puede dar una imagen de falsa aireación cuando el contenido mucoso es altamente proteico [2].

\section{MATERIAL Y MÉTODO}

Revisión sobre la aplicación de la RM en la patología nasosinusal según los protocolos del Complejo Asistencial de Zamora. Se realiza una revisión bibliográfica y se exponen las imágenes más representativas de algunos casos que se realizaron en nuestro centro en el período desde enero de 2011 hasta abril de 2016. El artículo está estructurado en cuatro bloques principales: anatomía, aplicación y protocolos de RM en patología nasosinusal, indicación de pruebas de imagen y hallazgos encontrados en RM de los principales procesos patológicos.

\section{ANATOMÍA DE INTERÉS EN LA RM NASOSINUSAL [3] \\ FOSAS NASALES. Son los espacios aéreos situa-} dos por encima de la cavidad oral, por debajo de las fosas craneales anteriores y delimitadas lateralmente por las órbitas y posteriormente por la nasofaringe con la que comunica a través de las coanas (Figura 1). Están separadas medianamente por el tabique nasal. Tiene dos regiones con localizaciones y funciones concretas: la respiratoria y la olfatoria, separadas a nivel del cornete medio (Figura 2). La región olfatoria se sitúa en la cara interna del cornete superior, el techo de la fosa nasal y las regiones adyacentes del tabique y de la pared lateral nasal. La región respiratoria es la más inferior y ocupa mayor extensión.

SENOS PARANASALES. Existen cuatro grupos de senos (Figura 3): frontales, maxilares, esfenoidales y complejo etmoidal. Los senos frontales se sitúan en el interior del hueso frontal, el tamaño es variable de un individuo a otro y de un lado a otro en un mismo individuo. Los senos maxilares son las cavidades que ocupan casi todo el espesor de la apófisis piramidal del hueso maxilar, es frecuente que tengan un desarrollo bilateral asimétrico con grosores de pared variables, en su parte superior se encuentra el ostium de salida. Los senos esfenoidales se localizan en el cuerpo del esfenoides y su tamaño es muy variable. El complejo etmoidal o celdillas etmoidales se localizan en el hueso etmoidal, presenta una lámina perpendicular que se extiende a nivel intracraneal denominándose apófisis crista galli.

FOSAS PTERIGOPALATINAS. Es una cavidad de morfología piramidal que se sitúa entre la apófisis perpendicular del hueso palatino anteriormente y la apófisis pterigoides del hueso esfenoides en su cara posterior.

\section{APLICACIÓN Y PROTOCOLOS DE LA RM EN PATOLOGÍA NASOSINUSAL}

La RM sigue siendo una prueba diagnóstica de imagen por detrás de la TC en la patología nasosinusal, dado que su resolución y capacidad para demostrar detalles finos del hueso es menor.

La gran ventaja de la RM es su capacidad para caracterizar alteraciones de partes blandas, 
siendo especialmente útil para la valoración de la extensión más allá de los senos paranasales tanto de patología inflamatoria como tumoral.

Dado que la mayoría de los estudios de RM de senos paranasales son solicitados para valoración de neoplasias y procesos inflamatorios, los protocolos suelen incluir secuencias sin y tras la administración de contraste paramagnético [1]. Existen casos en los que no se recomienda su administración como en el caso de pacientes con insuficiencia renal grave por el riesgo de fibrosis sistémica nefrogénica.
Se suelen emplear secuencias potenciadas T1 spin-echo sin saturación grasa en el estudio precontraste. Esta secuencia es útil para valorar las estructuras en torno a las cavidades nasosinusales, tales como las órbitas, los tejidos blandos premaxilares y la fosa pterigopalatina, y para buscar evidencias de infiltración de tejidos blandos en estas regiones que normalmente presentan una alta señal por su contenido en tejido adiposo, ya que esto puede ser un signo incipiente de extensión de la enfermedad más allá de los senos paranasales.

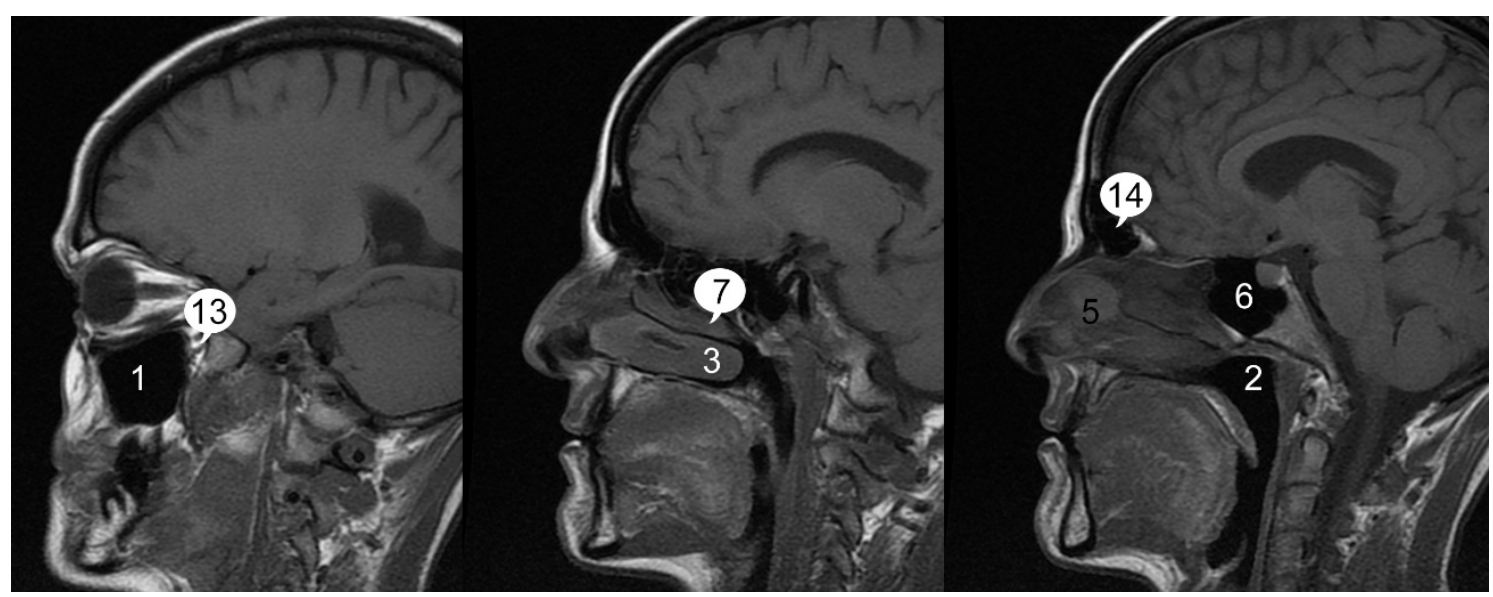

Figura 1. RM de senos paranasales. Anatomía. Secuencia T1. Plano sagital. 1. Seno maxilar, 2. Nasofaringe, 3. Cornete nasal inferior, 4. Fisura pterigomaxilar, 5. Tabique nasal, 6. Seno esfenoidal, 7. Cornete nasal medio, 8. Celdillas etmoidales anteriores, 9. Celdillas etmoidales posteriores, 10. Lámina perpendicular del etmoides, 11. Crista galli, 12. Cornete nasal superior, 13. Fosa pteropalatina, 14. Seno frontal.

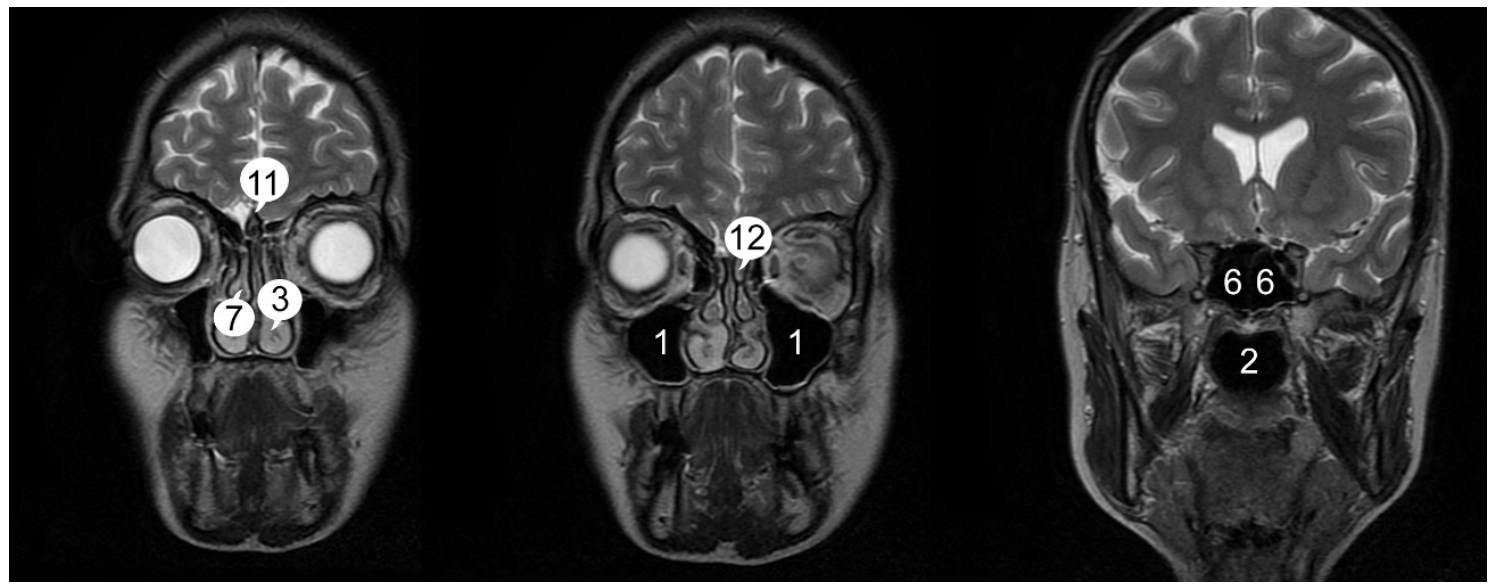

Figura 2. RM de senos paranasales. Anatomía. Secuencia T2. Plano coronal. 1. Seno maxilar, 2. Nasofaringe, 3. Cornete nasal inferior, 4. Fisura pterigomaxilar, 5. Tabique nasal, 6. Seno esfenoidal, 7. Cornete nasal medio, 8. Celdillas etmoidales anteriores, 9. Celdillas etmoidales posteriores, 10. Lámina perpendicular del etmoides, 11. Crista galli, 12. Cornete nasal superior, 13. Fosa pteropalatina, 14. Seno frontal. 


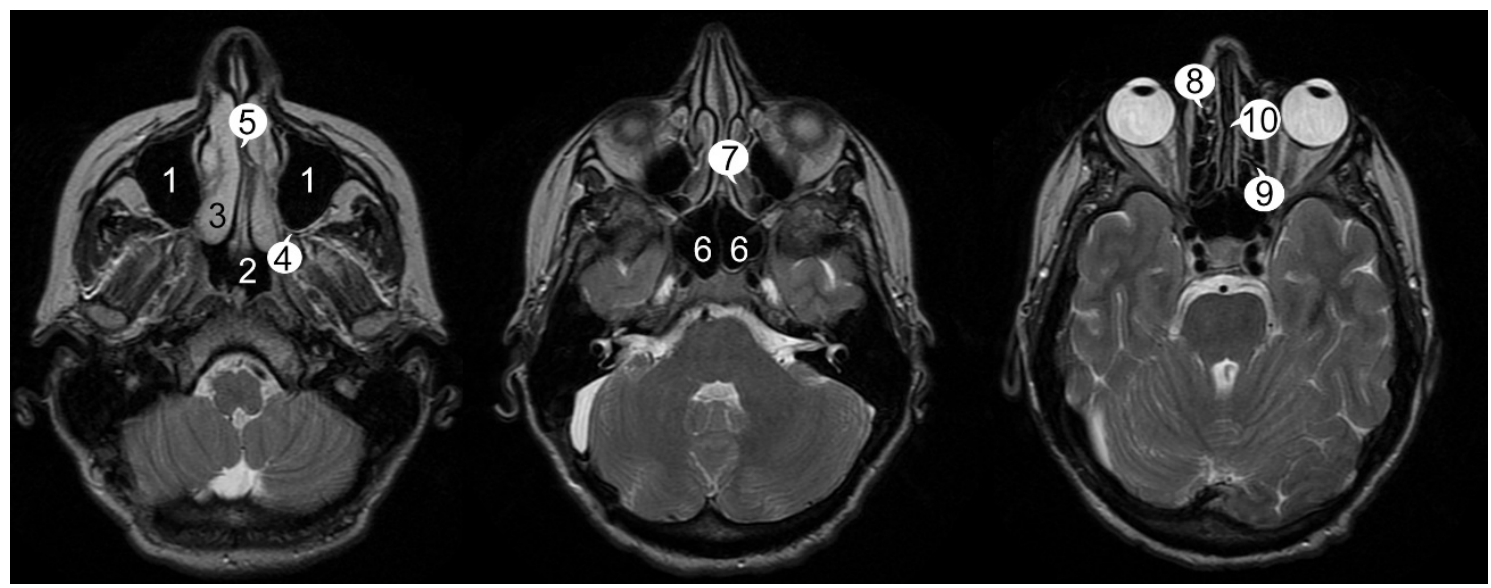

Figura 3. RM de senos paranasales. Anatomía. Secuencia T2. Plano axial. 1. Seno maxilar, 2. Nasofaringe, 3. Cornete nasal inferior, 4. Fisura pterigomaxilar, 5. Tabique nasal, 6. Seno esfenoidal, 7. Cornete nasal medio, 8. Celdillas etmoidales anteriores, 9. Celdillas etmoidales posteriores, 10. Lámina perpendicular del etmoides, 11. Crista galli, 12. Cornete nasal superior, 13. Fosa pteropalatina, 14. Seno frontal.

Para el estudio tras la administración de contraste se suelen realizar cortes finos $(\leq 4 \mathrm{~mm})$ empleando secuencias potenciadas en T1 con supresión grasa en los planos axial y coronal a los senos paranasales y la base del cráneo. Las secuencias con saturación grasa aumentan la sensibilidad delimitando mejor la lesión y facilitando la detección de la diseminación de la enfermedad perineural, la afectación de la base del cráneo y la extensión intracraneal. Otros autores incluyen en el protocolo secuencias T1 3D eco de gradiente tras la administración de contraste, especialmente útil para realizar reconstrucciones multiplanares y utilizarla en los sistemas de neuronavegación intraoperatoria [4].

Ante la sospecha de fístulas de líquido cefalorraquídeo [5] también pueden ser útiles las secuencias de alta resolución Balanced Fast Field Echo (Philips), TrueFISP (Siemens) y Fiesta (GE). La secuencia de difusión —-diffusion-weighted imaging (DWI) - suelen ser útiles para diferenciar neoplasias benignas y malignas, dado que las lesiones malignas tienen un coeficiente de difusión aparente (ADC) significativamente más bajo con respecto a los tumores benignos y las lesiones inflamatorias. Sin embargo, existe un solapamiento significativo del ADC de los procesos benignos y malignos; la exactitud diagnóstica global proporcionada por la medición del ADC $(79 \%$, según Sasaki M. y colaboradores) todavía no es adecuada para diferenciar de manera fiable entre los dos previo a la cirugía [6]. Por lo tanto, cuando se habla que una lesión nasosinusal tiene un ADC bajo nos referimos a que existe un alto grado de sospecha de malignidad. Se ha sugerido que la combinación de los estudios dinámicos tras la administración de contraste - dynamic contrast-enhanced (DCE)y las secuencias DWI podrían mejorar la capacidad para diagnosticar la malignidad de un tumor.

Sasaki M. y colaboradores han llegado a publicar una precisión del $100 \%$ en un pequeño número de casos, a pesar de que estos resultados parecen reproducirse en otros estudios, todavía no presentan una fiabilidad suficiente [7].

En la tabla 1 se muestran las secuencias del protocolo estándar de RM facial y senos paranasales que realizamos en nuestro centro.

Tabla 1. RM de senos paranasales. Protocolo estándar de RM facial/senos paranasales que realizamos en nuestro centro. Dependiendo del caso el grosor y el espacio entre los cortes pueden variar.

\begin{tabular}{|l|l|c|c|}
\hline Secuencia & Plano & Grosor & Espacio \\
\hline \multicolumn{4}{|c|}{ Pre-Contraste } \\
\hline T2 & Axial & 4,0 & 1,0 \\
\hline T1 FatSat & Axial & 4,0 & 1,0 \\
\hline T1 & Axial & 4,0 & 1,0 \\
\hline T1 & Sagital & 4,0 & 1,0 \\
\hline DP FatSat & Sagital & 4,0 & 1,0 \\
\hline T2 & Coronal & 4,0 & 1,0 \\
\hline DP FatSat & Coronal & 4,0 & 1,0 \\
\hline \multicolumn{4}{|l|}{ Post-Contraste } \\
\hline T1 FatSat + Gd & Axial & 4,0 & 1,0 \\
\hline T1 FatSat + Gd & Coronal & 4,0 & 1,0 \\
\hline
\end{tabular}


INDICACIONES EN EL USO DE LA RM EN PATOLOGÍA NASOSINUSAL

En cuanto a la indicación de las pruebas de diagnóstico por imagen, aunque actualmente forman parte rutinaria de los protocolos diagnósticos para la mayoría de los casos de sinusitis crónica y otras enfermedades nasosinusales — principalmente la TC_al igual que con cualquier otro procedimiento médico, hay que valorar los beneficios frente a los costes tanto económicos como en términos de potencial riesgo para los pacientes.

El American College of Radiology (ACR) publicó una actualización sobre los criterios de adecuación de pruebas de imagen en patología nasosinusal en 2013 [8]. Los criterios se resumen en la tabla 2 , se le asigna una calificación que va de 1 a 9 , puntuando de 1 a 3 las pruebas que por lo general no están indicadas, de 4 a 6 las pruebas apropiadas para casos seleccionados y de 7 a 9 las pruebas normalmente indicadas.

\section{HALLAZGOS DE RM EN PATOLOGÍA NASOSINUSAL}

Podemos dividir la patología nasosinusal en dos grandes grupos: patología inflamatoria y tumores nasosinusales. Como ya se ha visto previamente la técnica de elección para la valoración de los senos paranasales es la TC. Por el contrario, la RM presenta utilidad como estudio complementario, siendo posible encontrar patología nasosinusal incidental en estudios de RM realizados por otras causas.

Tabla 2. RM de senos paranasales. Indicaciones de Pruebas de Diagnóstico por Imagen en patología nasosinusal.

\begin{tabular}{|c|c|c|c|}
\hline Indicación & Prueba radiológica & Ptos & Comentarios \\
\hline \multirow[t]{2}{*}{$\begin{array}{l}\text { Sinusitis aguda (<4 sema- } \\
\text { nas) o subaguda ( } 4-12 \text { se- } \\
\text { manas) no complicada }\end{array}$} & TC de senos sin contraste & 5 & $\begin{array}{l}\text { Puede estar indicado si se sospecha sinusitis aguda fron- } \\
\text { tal o esfenoidal, si hay síntomas atípicos o si el diagnós- } \\
\text { tico es incierto. }\end{array}$ \\
\hline & $\begin{array}{l}\text { RM cerebral y de senos sin } \\
\text { contraste }\end{array}$ & 4 & $\begin{array}{l}\text { Puede ser útil como parte de un estudio diagnóstico ge- } \\
\text { neral para cefalea de reciente comienzo. }\end{array}$ \\
\hline \multirow{2}{*}{$\begin{array}{l}\text { Sinusitis aguda o crónica } \\
\text { recurrente (posible candi- } \\
\text { dato a cirugía) }\end{array}$} & TC de senos sin contraste & 9 & Dentro de protocolo de planificación quirúrgica. \\
\hline & TC de senos con contraste & 4 & --- \\
\hline \multirow{4}{*}{$\begin{array}{l}\text { Sinusitis aguda o suba- } \\
\text { guda con complicaciones } \\
\text { orbitarias o intracraneales } \\
\text { asociadas con déficit ocu- } \\
\text { lar o neurológico }\end{array}$} & $\begin{array}{l}\text { TC de senos y orbitas sin } \\
\text { contraste }\end{array}$ & 9 & $\begin{array}{l}\text { La RM y la TC son complementarios. El estudio cerebral } \\
\text { es esencial ante la sospecha de invasión del SNC. }\end{array}$ \\
\hline & $\begin{array}{l}\text { RM cerebral y de senos sin } \\
\text { y con contraste }\end{array}$ & 9 & $\begin{array}{ll}-- \\
-1\end{array}$ \\
\hline & $\begin{array}{l}\text { TC de senos y orbitas con } \\
\text { contraste }\end{array}$ & 8 & $\begin{array}{l}\text { Si es el único estudio que se puede realizar (por ejemplo, } \\
\text { si la RM está contraindicada), estaría indicado. }\end{array}$ \\
\hline & $\begin{array}{l}\text { RM cerebral y de senos sin } \\
\text { contraste }\end{array}$ & 7 & $\begin{array}{l}\text { Si no es posible emplear gadolinio (por ejemplo, insufi- } \\
\text { ciencia renal grave). }\end{array}$ \\
\hline \multirow[t]{4}{*}{$\begin{array}{l}\text { Sinusitis aguda o suba- } \\
\text { guda en pacientes inmu- } \\
\text { nosuprimidos }\end{array}$} & TC de senos sin contraste & 7 & $\begin{array}{l}\text { Estos pacientes tienen un alto riesgo de sinusitis fúngica } \\
\text { invasiva, lo que disminuye el umbral de los estudios de } \\
\text { imagen. }\end{array}$ \\
\hline & $\begin{array}{l}\text { RM cerebral y de senos sin } \\
\text { contraste }\end{array}$ & 6 & --- \\
\hline & $\begin{array}{l}\text { RM cerebral y de senos sin } \\
\text { y con contraste }\end{array}$ & 6 & --- \\
\hline & TC de senos con contraste & 5 & $\begin{array}{l}\text { Los estudios con contraste y las imágenes del cerebro } \\
\text { son esenciales si se sospecha invasión del SNC. }\end{array}$ \\
\hline \multirow{4}{*}{$\begin{array}{l}\text { Poliposis nasosinusal } \\
\text { (véase siguiente indica- } \\
\text { ción si es unilateral) }\end{array}$} & TC de senos sin contraste & 9 & --- \\
\hline & $\begin{array}{l}\text { RM cerebral y de senos sin } \\
\text { y con contraste }\end{array}$ & 4 & $\begin{array}{l}\text { Si se trata de afectación unilateral véase la siguiente in- } \\
\text { dicación (obstrucción nasosinusal, sospecha de masa). }\end{array}$ \\
\hline & $\begin{array}{l}\text { RM cerebral y de senos sin } \\
\text { contraste }\end{array}$ & 4 & $\begin{array}{ll}-- \\
-1\end{array}$ \\
\hline & TC de senos con contraste & 4 & --- \\
\hline \multirow[t]{6}{*}{$\begin{array}{l}\text { Obstrucción nasosinusal o } \\
\text { sospecha de masa }\end{array}$} & $\begin{array}{l}\text { RM cerebral y de senos sin } \\
\text { y con contraste }\end{array}$ & 9 & $\begin{array}{l}\text { La RM y la TC son complementarios. Ambos se necesi- } \\
\text { tan frecuentemente. }\end{array}$ \\
\hline & TC de senos sin contraste & 8 & --- \\
\hline & TC de senos con contraste & 6 & --- \\
\hline & $\begin{array}{l}\text { TC de senos sin y con con- } \\
\text { traste }\end{array}$ & 6 & --- \\
\hline & $\begin{array}{l}\text { RM cerebral y de senos sin } \\
\text { contraste }\end{array}$ & 5 & $\begin{array}{l}\text { Si no es posible emplear gadolinio (por ejemplo, insufi- } \\
\text { ciencia renal grave). }\end{array}$ \\
\hline & Arteriografía craneofacial & 4 & $\begin{array}{l}\text { Está indicado en casos seleccionados (por ejemplo, } \\
\text { compromiso vascular o lesión hipervascular). }\end{array}$ \\
\hline
\end{tabular}

Escala de valoración: 4, 5 y 6: puede estar indicado; 7, 8 y 9: generalmente está indicado. Los procedimientos con una valoración de 1, 2 ó 3 (generalmente no está indicado) no se incluyen en esta tabla. Adaptado de Cornelius RS, et al. [8]. 
PATOLOGÍA INFLAMATORIA NASOSINUSAL

En este apartado se incluye la rinosinusitis aguda y crónica, la sinusitis fúngica, los quistes de retención, los pólipos y el mucocele.

\section{RINOSINUSITIS}

Los estudios de imagen no suelen ser necesarios en el contexto de sinusitis, salvo en los casos en los que se sospeche la existencia de complicación, en las situaciones de sinusitis aguda sobre sinusitis crónica y en la sinusitis recurrente. Los hallazgos típicos son engrosamiento inespecífico de la mucosa, edema submucoso, niveles hidroaéreos o cúmulo de secreciones en los senos paranasales [9]; hipointensos en $\mathrm{T} 1$ e hiperintensos en T2 ( $\mathrm{Fi}$ gura 4). Un nivel hidroaéreo en el seno como único hallazgo es bastante característico de la sinusitis aguda, pero no está presente en todos los pacientes [10]. La distribución puede dar una pista sobre la causa de la enfermedad aguda, así la sinusitis alérgica es generalmente más difusa y la sinusitis bacteriana suele ser más localizada o asimétrica [11]. La RM es más sensible en la detección del engrosamiento de la mucosa que la TC [10]. Se puede considerar normal un engrosamiento de la mucosa de hasta $3 \mathrm{~mm}$ en los senos maxilares en pacientes sanos, considerándose anormal cualquier engrosamiento en la mucosa de los senos frontales y esfenoidales, siendo probable la aparición de clínica concomitante en estos casos. En las celdillas etmoidales el engrosamiento de la mucosa de hasta $2 \mathrm{~mm}$ se puede atribuir al fenómeno fisiológico del ciclo nasal si se visualiza un engrosamiento de la mucosa de la cavidad nasal y la prominencia de los cornetes nasales ipsilaterales [12].

Los hallazgos más frecuentes en el caso de sinusitis crónica son el engrosamiento de la mucosa, cambios en el hueso adyacente como irregularidad $\mathrm{o}$ incluso adelgazamiento del mismo (valorables mediante TC) y cúmulo de secreciones con alto contenido proteico que normalmente se apreciará hiperintenso en T1 (dependiendo de la proporción de proteínas en las secreciones). Las calcificaciones son infrecuentes y, cuando se ven, suelen ser periféricas y dispersas, las redondas o en "cáscara de huevo" son más habituales en pacientes con rinosinusitis crónica inflamatoria [13]. Si el engrosamiento mucoso no realza tras la administración de contraste hay que pensar en una fase fibrótica con áreas cicatriciales en lugar de en un proceso inflamatorio-infeccioso activo [10] (Figura 5).

\section{SINUSITIS FÚNGICA}

Clínicamente se clasifica en invasiva y no invasiva. La forma invasiva se caracteriza por la presencia de hifas en la mucosa, submucosa, vasos y hueso de los senos paranasales. Dentro de ésta se describen tres tipos, aguda, crónica y crónica granulomatosa. La no invasiva no presenta hifas en ningún componente estructural de los senos y puede expresarse como sinusitis fúngica alérgica o bola fúngica $[14,15]$.

En RM la apariencia de las secreciones depende de su contenido proteico, viscosidad y presencia de calcificaciones. Las secreciones acuosas generalmente contienen menos del $5 \%$ de proteína, visualizándolas hipointensas en T1 e hiperintensas en T2. A medida que aumenta el contenido proteico de las secreciones la señal va cambiando, siendo hiperintensa en T1 y normalmente hipointensa en T2 cuando el contenido proteico supone el $25 \%$ al $30 \%$ ( $\mathrm{Fi}-$ gura 6 ). En las secreciones de elevada viscosidad y en presencia de bola fúngica, donde el contenido proteico supone hasta el $40 \%$ se visualiza una señal baja en T1 y T2, incluso no presentando señal. Este último patrón es muy sugerente de sinusitis fúngica [16].

\section{QUISTES DE RETENCIÓN}

Se trata de un hallazgo frecuente en pacientes con sinusitis crónica, aunque puede ser un hallazgo incidental en población sana. Se forman como resultado de la obstrucción de las glándulas mucinosas submucosas (quistes de retención mucosa) o cúmulo de líquido en la capa submucosa (quistes de retención serosa), siendo ambas formas indistinguibles desde el punto de vista del estudio de imagen. Son más frecuentes en los senos maxilares. En RM se identifican formaciones convexas hacia la luz del seno hipointensas en T1 e hiperintensas en T2 [10].

\section{PÓLIPOS}

Son las masas expansivas más frecuentes del área nasosinusal. Pueden ser únicos y no diferenciarse de los quistes de retención. También puede ser múltiples y ocupar por completo la cavidad nasal en el proceso denominado poliposis nasosinusal. Por lo general son pequeños, pero pueden crecer y llegar a erosionar las paredes óseas de los senos paranasales. Normalmente están separados de las paredes óseas por una capa delgada de material mucoide. En RM la intensidad de señal de los pólipos es heterogénea en T1 y T2, dependiendo 
del contenido en agua y proteínas (Figura 7). Cuando la concentración de material proteico es alta las señales pueden llegar a ser hipointensas en ambas secuencias, simulando un seno normalmente aireado [10].

El pólipo antrocoanal es una lesión que crece en el seno maxilar pudiendo ocasionar su opacificación completa y extenderse posteriormente a través del ostium hasta la cavidad nasal y la nasofaringe [17]. Los pólipos etmocoanal y esfenocoanal son raros [18].

\section{MUCOCELE}

Se trata de una lesión expansiva y quística, delimitada por una membrana mucosa. Se forma por la acumulación de secreciones y descamación.

A diferencia de los quistes de retención, los mucoceles rellenan completamente el seno y suelen producir dehiscencia de sus paredes. El seno frontal es el que se afecta con más frecuencia, seguido del etmoidal.

La cavidad sinusal debe estar expandida para llegar al diagnóstico de mucocele, llegando a ocasionar destrucción ósea. La apariencia en RM depende, como hemos visto previamente, del contenido proteico (Figura 8) [10].

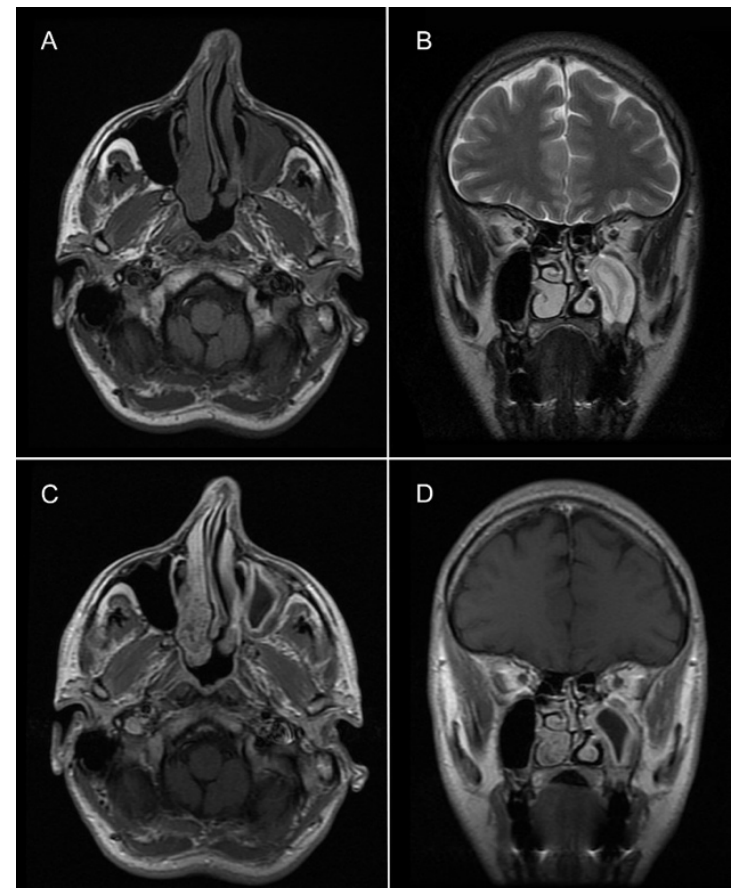

Figura 4. RM de senos paranasales. Sinusitis aguda. (A) Secuencia T1 en el plano axial. (B) Secuencia T2 en el plano coronal. (C) Secuencia T1 Saturación grasa tras la administración de contraste en el plano axial. (D) Secuencia T1 saturación grasa tras la administración de contraste en el plano coronal. Se observa un marcado engrosamiento mucoperióstico en el seno maxilar izquierdo y cúmulo de secreciones que ocupa totalmente el seno, tras la administración de contraste se puede apreciar el intenso realce la mucosa.
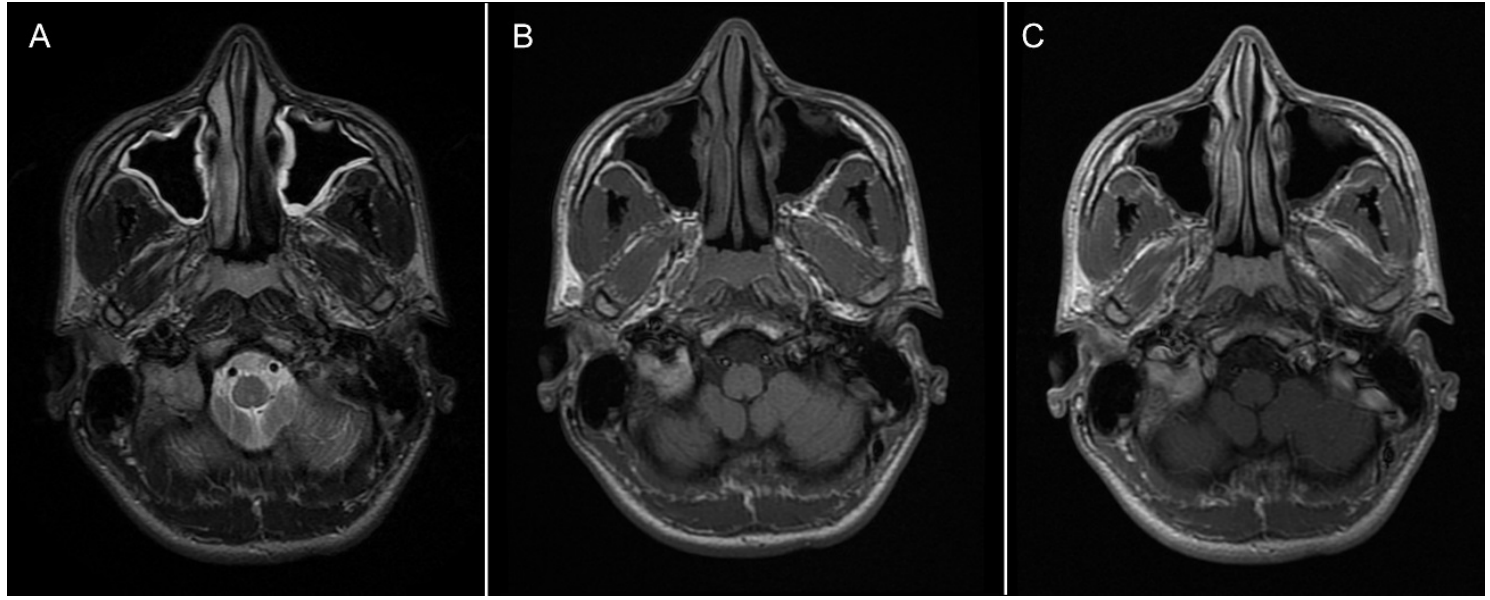

Figura 5. RM de senos paranasales. Sinusitis crónica. (A) Secuencia T2 en el plano axial. (B) Secuencia T1 en el plano axial. (C) Secuencia T1 tras la administración de contraste en el plano axial. Se observa un engrosamiento de la mucosa de ambos senos maxilares sin realce tras la administración de contraste, lo que indica fase crónica y no proceso infeccioso activo. 

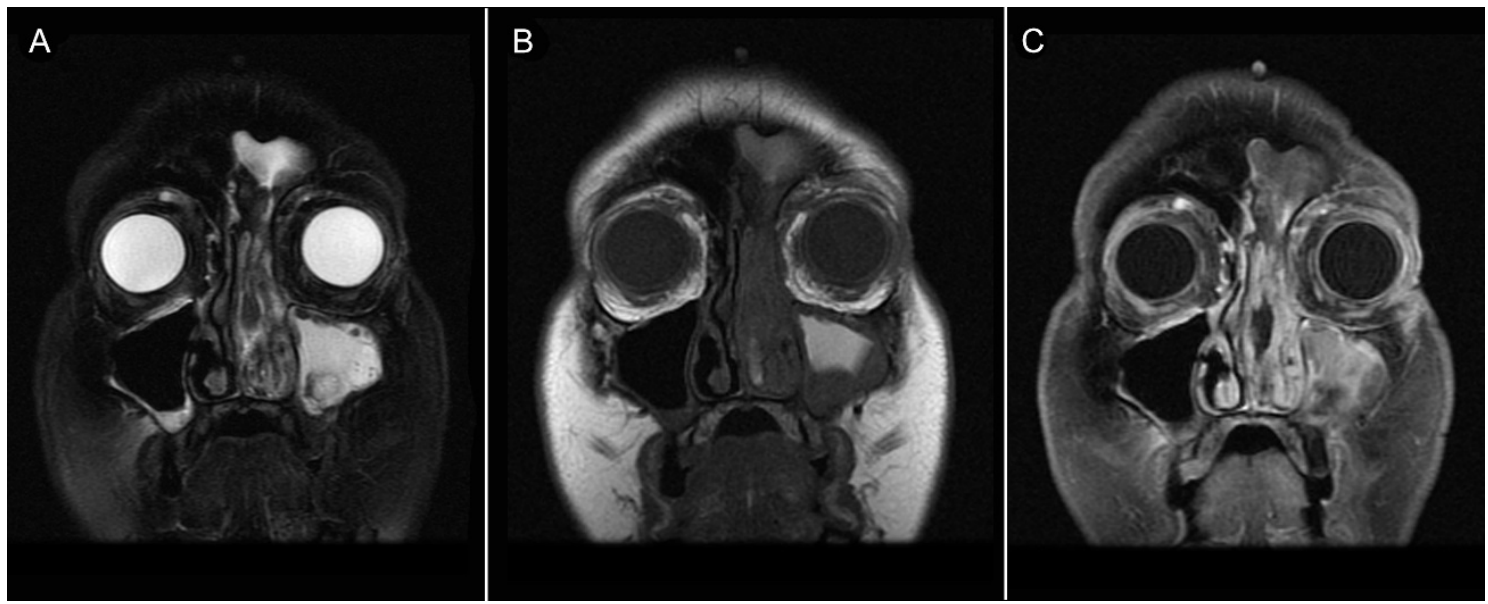

Figura 6. RM de senos paranasales. Sinusitis fúngica. (A) Secuencia T2 saturación grasa en el plano coronal. (B) Secuencia T1 en el plano coronal. (C) Secuencia T1 saturación grasa tras la administración de contraste en el plano coronal. Se observa un engrosamiento irregular de la mucosa de la fosa nasal, seno maxilar, celdillas etmoidales y seno frontal izquierdos con calcificaciones en "cascara de huevo" en la porción inferior del seno maxilar y cúmulo de secreciones hiperintensas en T1 lo que indica un alto contenido proteico (entre el $25 \%-30 \%$ ) y un realce heterogéneo.

\section{TUMORES NASOSINUSALES}

La cavidad nasal y los senos paranasales son el lugar de origen de un grupo complejo y variado de neoplasias, dados los diferentes tejidos existentes en esta región anatómica. Las neoplasias nasosinusales suponen el $3 \%$ de todos los tumores de cabeza y cuello [19]. La mayoría de estos tumores son similares a los encontrados en otras partes del cuerpo, pero otros como el neuroblastoma olfatorio, son exclusivos de esta localización. En ocasiones las fosas nasales pueden contener cuerpos extraños que ocasionan síntomas y signos clínicos similares a los de los tumores (obstrucción nasal y epistaxis).

Hay que tener en cuenta que muchos de los tumores nasosinusales se diagnostican en estadio avanzado por múltiples factores: los espacios aéreos permiten una progresión del tumor sin sintomatología dolorosa o con síntomas semejantes a patología inflamatoria (congestión nasal), muchas de las neoplasias de esta región son muy agresivas lo que contribuye al mal pronóstico, se trata de una región anatómica con importante vascularización linfática y próxima a estructuras anatómicas vitales (orbitas, base del cráneo, fosa pterigopalatina) y son tumores que no suelen ocasionar dolor hasta el final de la enfermedad a pesar de que ocasionen destrucción ósea [19].
El papel de las pruebas de diagnóstico por imagen es [20, 21]:

- Limitar los posibles diagnósticos diferenciales.

- Distinguir entre lesiones benignas y malignas.

- Valorar extensión del tumor y su relación con estructuras anatómicas adyacentes.

- Seguimiento postratamiento.

TUMORES MALIGNOS.

El carcinoma epidermoide es la forma más frecuente y constituye el $80 \%$ al $90 \%$ de las neoplasias malignas (Figura 9). Le siguen en frecuencia el linfoma, los carcinomas de las glándulas salivales y los adenocarcinomas, que en conjunto son responsables del $10 \%$. El neuroblastoma olfatorio o estesioneuroblastoma (Figura 10) es una neoplasia de origen neuroectodérmico que se origina del epitelio olfatorio, localizada de forma característica en el techo de las fosas nasales, se trata de una lesión infrecuente que supone el $2 \%$ al $3 \%$ de los tumores malignos del tracto nasosinusal [22].

Las características radiológicas de una neoplasia maligna nasosinusal pueden ser variadas. No existe evidencia suficiente para que una prueba de imagen llegue a un diagnóstico patológico concluyente en la mayoría de los casos. Un enfoque estructurado ayuda al diag- 
nóstico diferencial. Los siguientes puntos radiológicos extraídos del artículo Imaging Approach to Sinonasal Neoplasms de Sen y colaboradores, plantean la sospecha de un tumor maligno en el espacio nasosinusal [19] (Figuras 9,10 y 11 ):

1. Participación de un solo compartimento.

2. Voluminosa masa de tejido blando con realce heterogéneo y necrosis. Generalmente señal intermedia en las secuencias potenciadas en $\mathrm{T} 2$.

3. Erosión y destrucción del hueso.

4. Extensión a múltiples compartimentos contiguos con destrucción de sus límites, ya sea de hueso o cartílago. Invasión de estructuras adyacentes.

5. Diseminación perineural.

La RM también es útil para valorar la diseminación de las neoplasias. Casi todos los tumores presentan dos períodos: uno inicial en el que existe sintomatología leve e inespecífica y otro final en el que el tumor se ha extendido localmente y el paciente presenta síntomas relacionados con la invasión de las estructuras afectadas [23].

Se va a producir una extensión local objetivada como alteraciones óseas, obliteración y mala definición de los planos grasos con claro aumento de partes blandas. En el $80 \%$ de los casos el seno maxilar estará implicado, porque es la localización primaria más frecuente y porque es la que se afecta por contigüidad de forma más habitual [23]. Para la valoración de la extensión local a través de la lámina papirácea y la placa cribiforme resulta útil la secuencia T2 en el plano coronal en la que se puede llegar a valorar la integridad de la interfase entre las cavidades nasosinusales y las estructuras vecinas identificando una línea hipointensa que corresponde al hueso y periostio y una línea hiperintensa que corresponde al líquido cefalorraquídeo. La secuencia T1 en el plano sagital tras la administración de contraste es especialmente útil para la valoración de extensión intracraneal y para diferenciar entre invasión extradural e intradural.

En cuanto a la extensión a distancia se produce mediante diseminación linfática, hematógena y perineural. Las metástasis ganglionares se observan en el $5 \%$ al $20 \%$ de los pacientes en el momento del diagnóstico. Las metástasis por vía hematógena suceden en el $10 \%$ de los casos, siendo más frecuentes en el carcinoma adenoide quístico y el melanoma, y se suelen localizar en pulmones, hígado y cerebro. La diseminación perineural es una forma muy característica de los tumores nasosinusales dada su localización, se extienden a través de la vaina del nervio y se pueden dirigir hacia su origen craneal y menos frecuentemente hacia la periferia. La aparición de la diseminación perineural puede ocurrir después de un periodo largo del tiempo tras el diagnóstico del tumor original y producir sintomatología inespecífica incluso una función del nervio normal, los hallazgos en imagen suelen ser sutiles: aumento del tamaño del foramen, destrucción del foramen, obliteración de los planos grasos, agrandamiento del nervio, realce del nervio, atrofia neuropática, convexidad de la pared lateral del seno cavernoso y obliteración de la cisterna subaracnoidea del trigémino $[19,20]$.
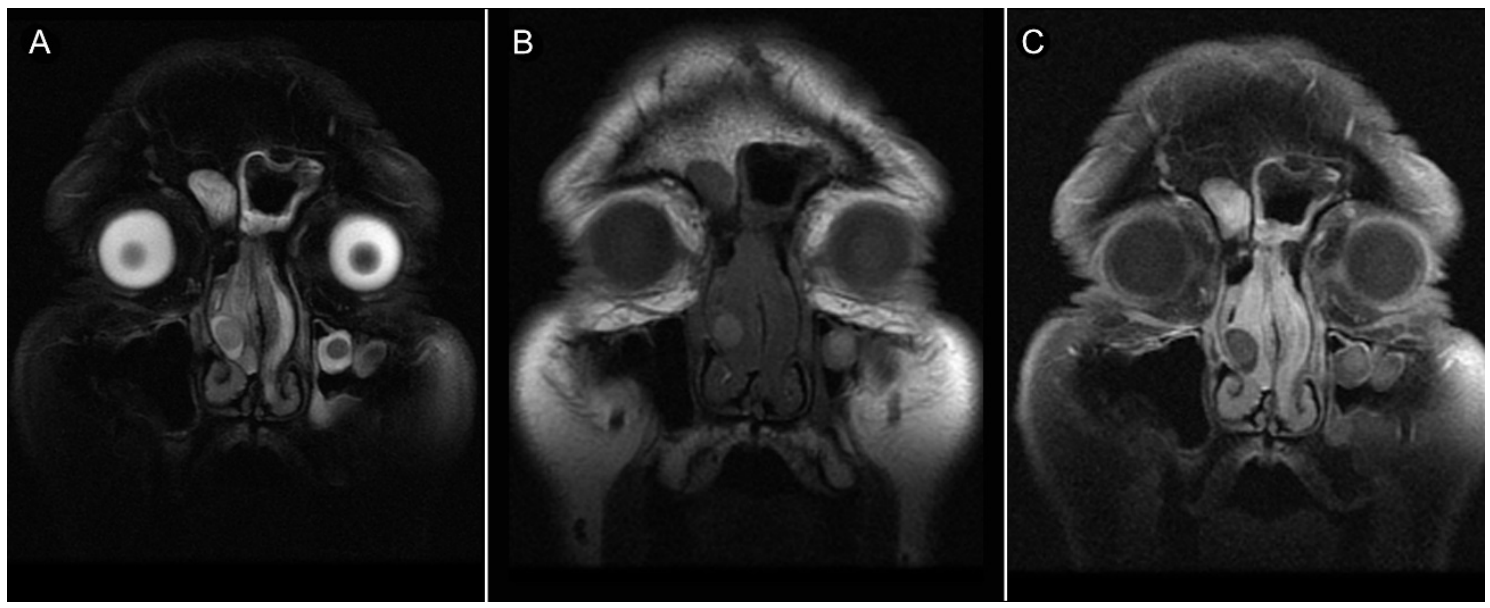

Figura 7. RM de senos paranasales. Poliposis. (A) Secuencia T2 saturación grasa en el plano coronal. (B) Secuencia T1 en el plano coronal. (C) Secuencia T1 saturación grasa tras la administración de contraste en el plano coronal. Se visualizan dos pólipos en el seno maxilar izquierdo y uno en la fosa nasal derecha. En la secuencia T1 de identifican como imágenes redondeadas discretamente hiperintensas por su contenido proteico sin objetivar un realce significativo tras la administración de contraste. 

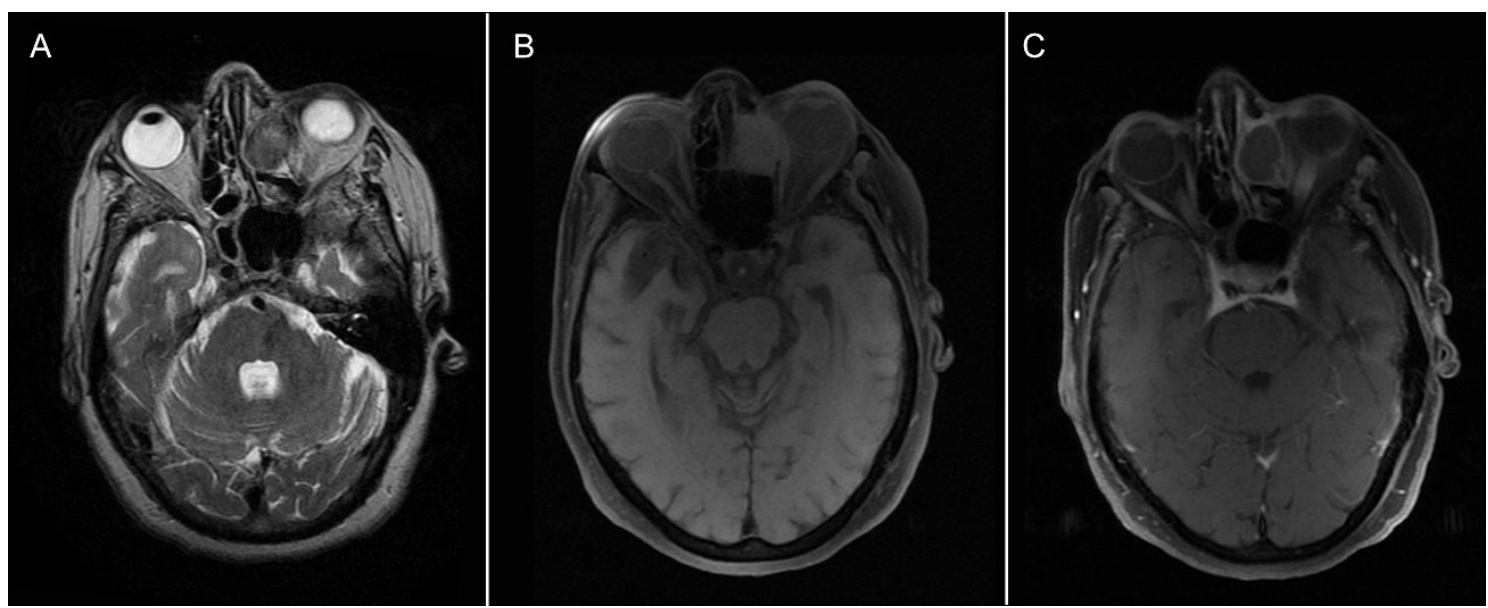

Figura 8. RM de senos paranasales. Mucocele. (A) Secuencia T2 en el plano axial. (B) Secuencia T1 saturación grasa en el plano axial. (C) Secuencia T1 saturación grasa tras la administración de contraste en el plano axial. Se aprecia una lesión expansiva que deforma la lámina perpendicular del etmoides y la lámina papirácea en celdillas etmoidales izquierdas, discretamente hipointensa en T2, isointensa en T1 y con realce de su pared tras la administración de contraste.

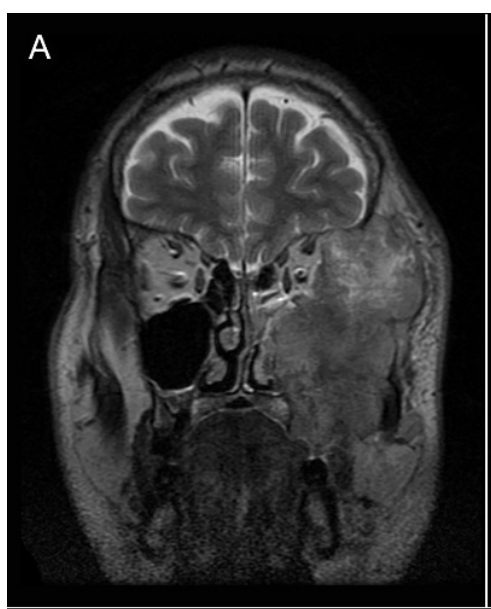

$\mathrm{D}$

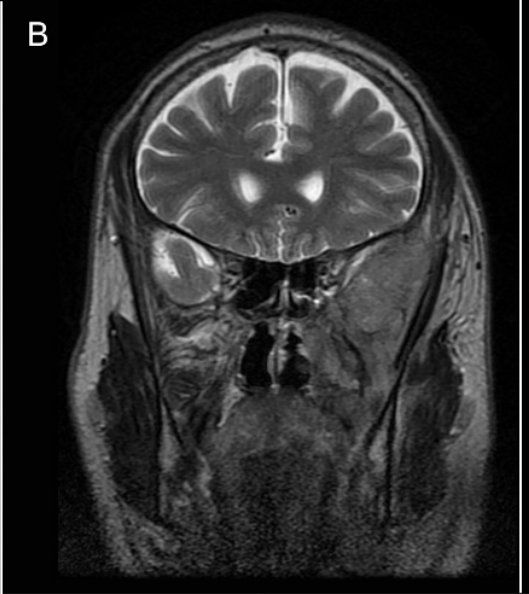

E
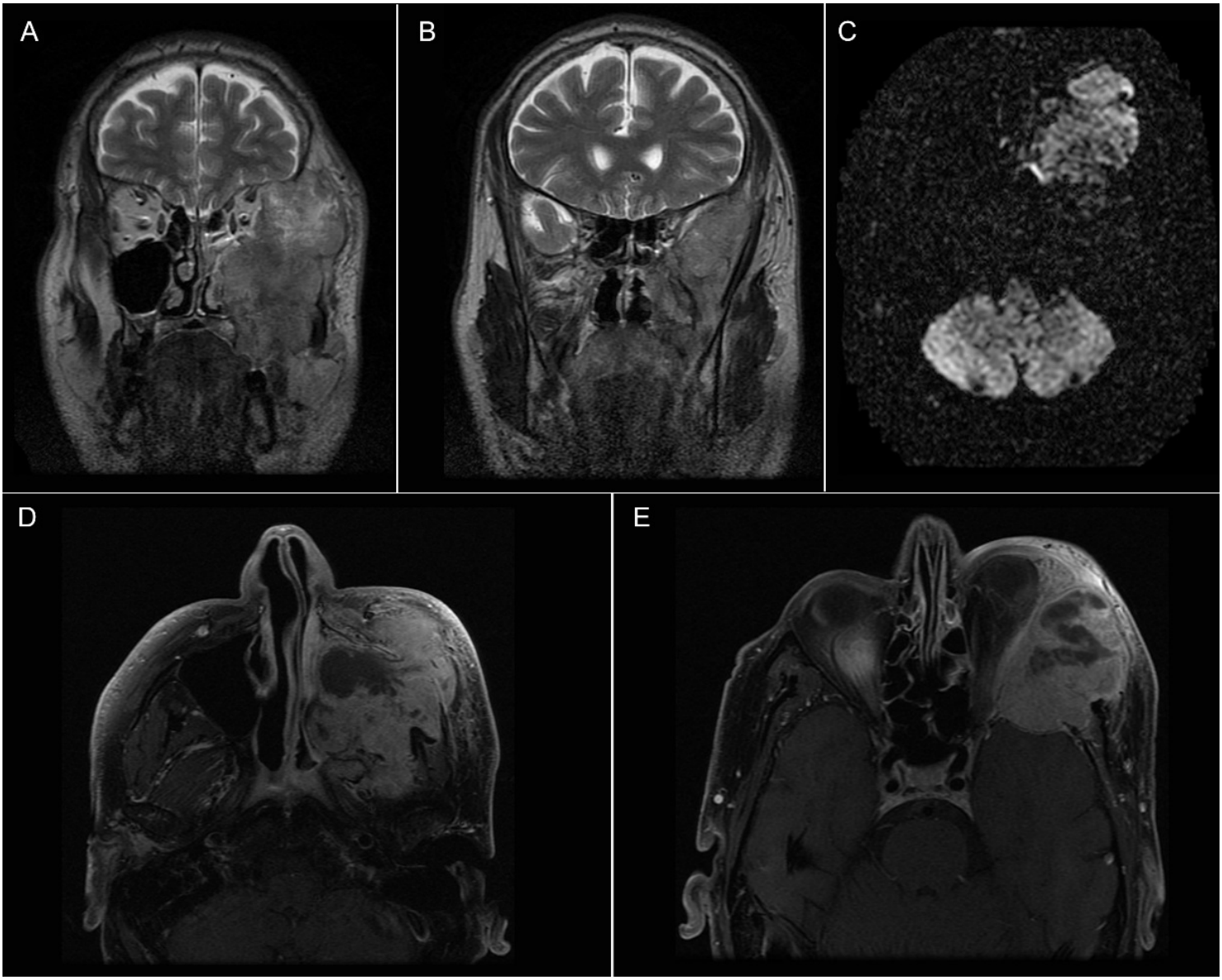

Figura 9. RM de senos paranasales. Carcinoma epidermoide en seno maxilar izquierdo. (A, B) Secuencia T2 en el plano coronal. (C) Secuencia DWI en el plano axial. (C, D) Secuencia T1 saturación grasa tras la administración de contraste en el plano axial. Se aprecia una masa heterogénea que ocasiona destrucción del suelo, paredes medial, lateral y superior del seno maxilar con invasión de la fosa nasal, órbita, fosa pterigopalatina y fosa temporal extradural. Existe restricción a la difusión, lo que sugiere alta celularidad. Tras la administración de contraste se objetiva intenso realce con área de necrosis central. 

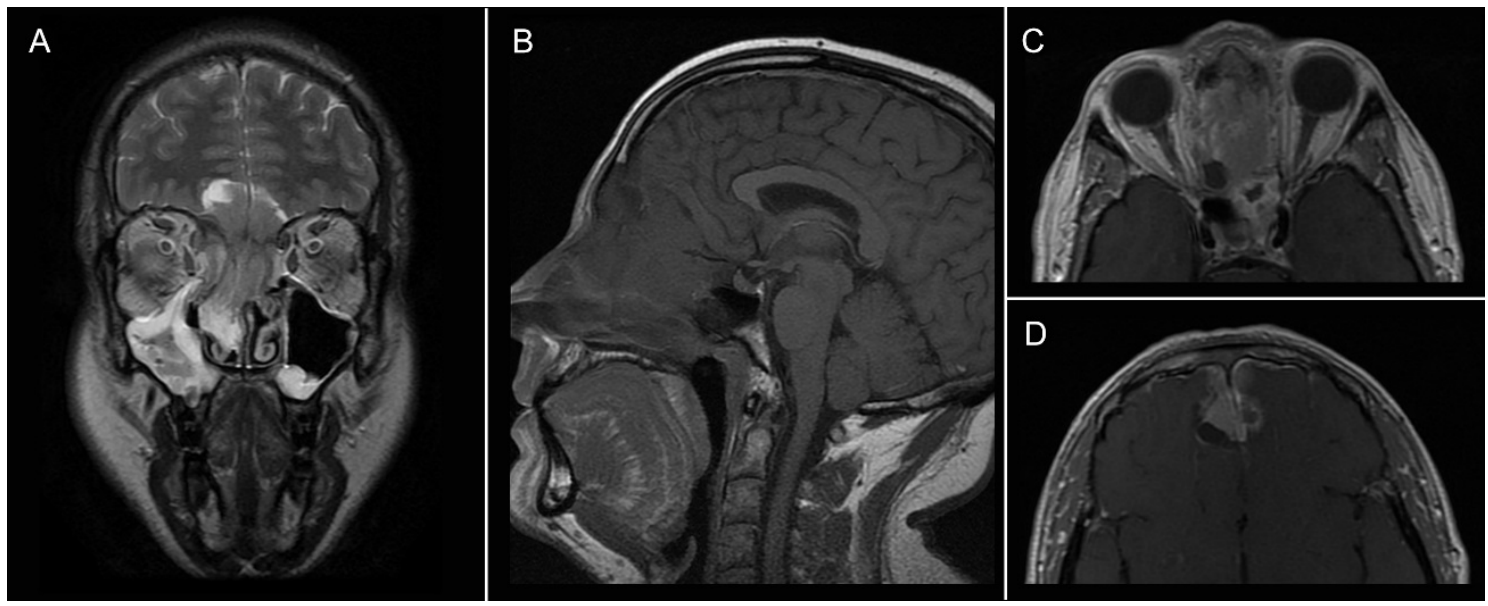

Figura 10. RM de senos paranasales. Neuroblastoma olfatorio. (A) Secuencia T2 en el plano coronal. (B) Secuencia T1 en el plano sagital. (C, D) Secuencia T1 tras la administración de contraste en el plano axial. Se identifica una masa heterogénea con zonas de degeneración quística, localizada de forma característica en el techo de las fosas nasales. Existe invasión del hueso frontal e intracraneal, con afectación meníngea pero no intraaxial.
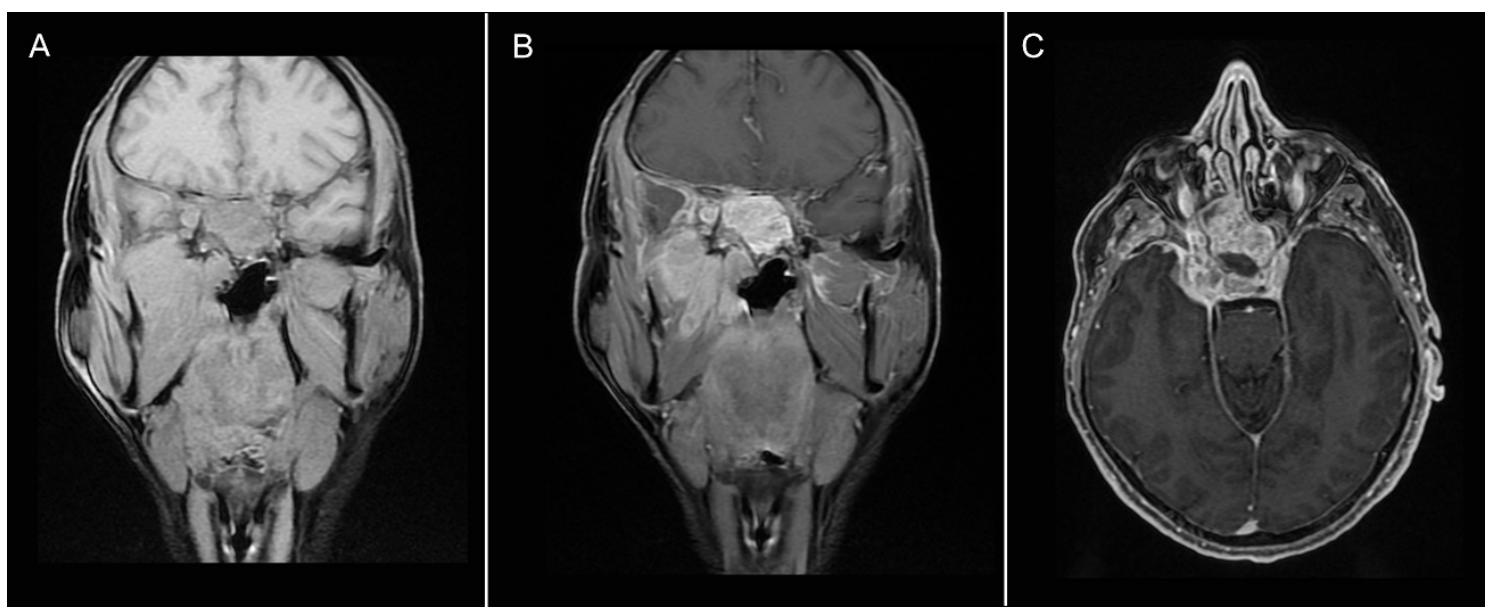

Figura 11. RM de senos paranasales. Carcinoma linfoepitelioide en seno esfenoidal. (A) Secuencia T1 saturación grasa en el plano coronal. (B) Secuencia T1 saturación grasa tras la administración de contraste en el plano coronal. (C) Secuencia 3D T1 saturación grasa tras la administración de contraste en el plano axial. Se observa una masa en el seno esfenoidal que invade la fosa pterigopalatina derecha, el seno cavernoso y fosa temporal extradural. Tras la administración de contraste se aprecia un intenso realce con áreas de necrosis.

\section{TUMORES BENIGNOS}

PAPILOMA SCHNEIDERIANO. Deriva de la mucosa respiratoria o membrana pituitaria que tapiza la cavidad nasal y los senos paranasales. Se clasifican en: invertido, oncocítico y exofítico [24]. Constituyen del $0,4 \%$ al $4,7 \%$ de todos los tumores nasosinusales [20].

El papiloma invertido es un papiloma en el cual el epitelio se invagina y prolifera en el estroma subyacente. Es el más frecuente de los papilomas nasales. El carcinoma escamoso puede coexistir en 5,5 al $27 \%$ de los casos [2].
Los otros dos tipos son menos frecuentes, el oncocítico se localiza de forma preferente en la pared lateral y el exofítico en la medial [2].

\section{Características en pruebas de imagen [20]:}

- De pequeñas lesiones polipoides no específicas a grandes masas con realce significativo.

- Ampliación y remodelación de la cavidad nasal con abombamiento de paredes óseas adyacentes.

- Adelgazamiento, esclerosis, fragmentos óseos dentro del tumor. 
- Patrón cerebriforme u ondulado en forma difusa o parcial en las secuencias T2 y T1 con contraste.

El papiloma invertido y oncocítico son potencialmente malignos. En RM el estudio dinámico tras la administración de contraste ha demostrado ser útil en la diferenciación del papiloma invertido de los tumores malignos de senos paranasales [25].

ANGIOFIBROMA DE CÁVUM. Se trata de un tumor mesenquimal benigno, pero localmente agresivo compuesto por elementos fibrosos y vasculares en proporción variable. Representa menos del $0,5 \%$ de todas las neoplasias nasofaríngeas [26]. De forma característica ocurre en varones adolescentes que presentan una clínica de obstrucción nasal y epistaxis.

Características en pruebas de imagen (Figura 12) [20]:

- Se localiza de forma primaria en la fosa pterigopalatina. Posteriormente se extiende de forma muy característica a la cavidad nasal y lateralmente se continúa con la cisura pterigomaxilar en la fosa infratemporal. Erosiona e invade la raíz de la apófisis pterigoides y posteriormente alcanza el ala mayor del esfenoides.

- Señal heterogénea en secuencias T1 y T2, con intenso realce tras la administración de contraste.

- Ensanchamiento de la fosa pterigopalatina y abombamiento de la pared posterior del seno maxilar.

- La vascularización depende de la arteria maxilar interna y la arteria faríngea ascendente.

OSTEOMA. Es un tumor óseo benigno formado por la proliferación de hueso maduro con una estructura lamelar predominante. Generalmente se detectan de manera incidental, pero el $37 \%$ se asocia con hallazgos patológicos nasosinusales [27]. Puede bloquear la vía de drenaje lacrimal o nasosinusal y ocasionar acumulación de secreciones.

Características en pruebas de imagen [20]:

- Se suelen localizar en seno frontal y etmoidal.

- Se suele identificar una amplia base o pedículo.

- Iso o hipointenso en las secuencias T2.
- Mejor valoración mediante TC.

En la evolución natural el osteoma crece lentamente y no maligniza, por lo que en la mayoría de los casos se recomienda un control periódico.

DISPLASIA FIBROSA. Es una enfermedad ósea idiopática que puede afectar a uno (monostótica) o múltiples huesos (poliostótica). En raras ocasiones puede formar parte del síndrome de McCune-Albright en el que se asocian con disfunción endocrina autoinmune y manchas «café con leche» en la piel. Fisiopatológicamente, la médula del hueso afectado es reemplazado por tejido inmaduro, que varía entre un espectro de tejido óseo y fibroso. El $0,5 \%$ de las formas poliostótica y el $4 \%$ de los pacientes con síndrome de McCune-Albright desarrollan una transformación maligna [28].

Características en pruebas de imagen [20]:

- Puede afectar a cualquier hueso craneofacial, sobre todo en su forma poliostótica. $\mathrm{Si}$ la afectación es profusa se denomina «leontiasis ósea».

- Señal intermedia en T1 e hipointensa en T2.

- Tras la administración de contraste se observa un realce de moderado a marcado.

- En TC se visualiza el hueso con adelgazado cortical, márgenes mal definidos y una matriz que varía de "aspecto algodonoso" a «vidrio esmerilado» en relación a su composición patológica.

QUISTE PERIODONTAL O QUISTE RADICULAR. Son IOS quistes maxilares más comunes. Surgen en los dientes con caries en la región periapical, como resultado de infecciones repetidas y la formación de granulomas. Son comunes en pacientes de edad media y son indoloros [29].

Características en pruebas de imagen [20]:

- Se localizan en el maxilar, en relación con dientes extraídos o desplazados, y erosionan el suelo del seno.

- Quiste uniloculado, hiperintenso en T2, con pared fina calcificada. 

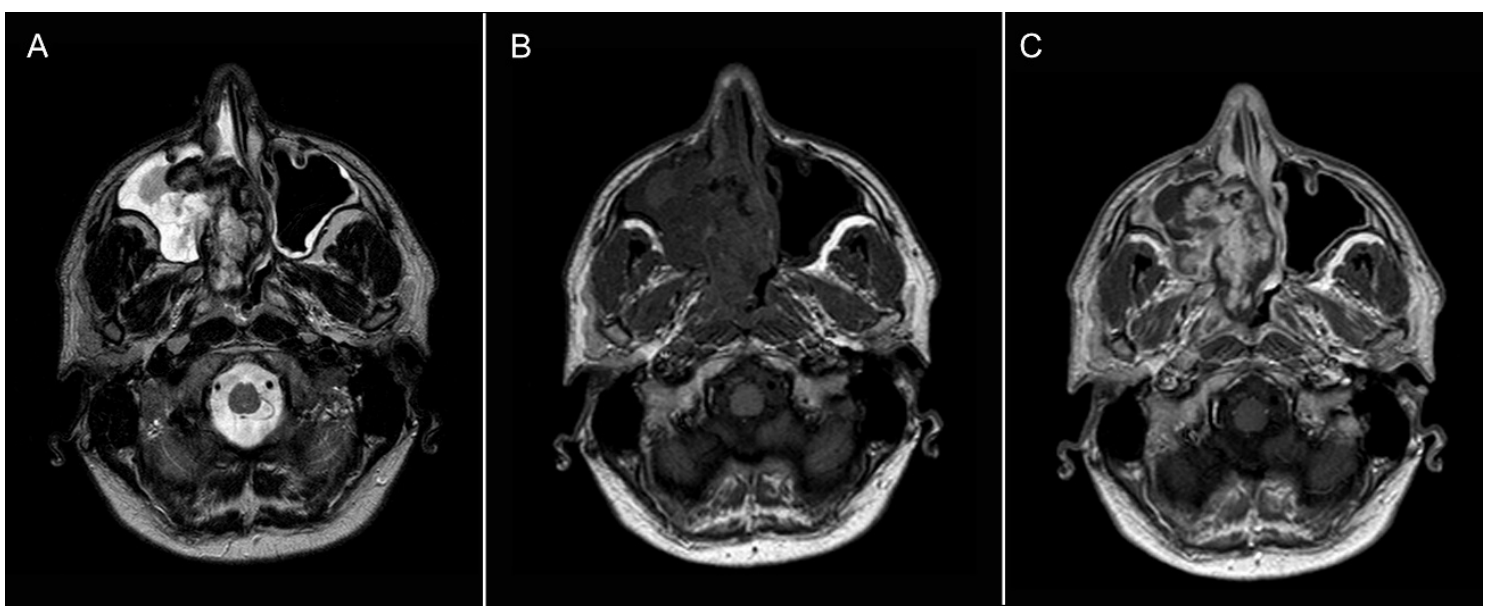

Figura 12. RM de senos paranasales. Angiofibroma. (A) Secuencia T2 en el plano axial. (B) Secuencia T1 en el plano axial. (C) Secuencia T1 tras la administración de contraste en el plano axial. Se observa una masa heterogénea de origen en la fosa pterigopalatina derecha con extensión a la fosa nasal y seno maxilar ipsilaterales. Tras la administración de contraste se aprecia un intenso realce heterogéneo.

\section{VALORACIÓN POSTRATAMIENTO}

Es habitual realizar controles postratamiento de tumoraciones, tanto benignas como malignas, principalmente cuando se sospechan complicaciones. A continuación, se expondrán cambios post-cirugía y posradioterapia (Figuras 13 y 14).

Después de la cirugía el seguimiento se realiza principalmente mediante RM con el objetivo de detectar restos tumorales o recidivas y valorar posibles complicaciones (por ejemplo el mucocele) [21]. La PETTC con 18F-fluorodesoxiglucosa (18F-FDG) puede resultar también útil para la re-estadificación en pacientes tratados por neoplasias malignas de senos paranasales. Una ventaja importante de la PET-TC con $18 \mathrm{~F}-\mathrm{FDG}$ es que un estudio de cuerpo entero permite la detección de metástasis a distancia y neoplasias secundarias no conocidas. Al igual que en la TC y la RM, la inflamación postquirúrgica y postradioterapia pueden causar una leve, incluso alta, actividad metabólica sin que signifique recidiva tumoral. A pesar de esto, la actividad metabólica es útil para distinguir el tejido cicatricial de las recidivas. Además un estudio negativo de PET-TC parece ser más predictivo de la ausencia de enfermedad [21].

En el caso de tumores con invasión intracraneal operados y con reconstrucción dural, en los primeros controles es habitual identificar la duraplastia como una placa con distintas capas bastante regular de 3 a $5 \mathrm{~mm}$ de espesor. En pocos meses el espesor se reduce en un $50 \%$ [30]. En el caso de cirugías que requieren reconstrucción de planos grasos, musculares y piel, el edema y realce de los tejidos que rodean el colgajo se observa generalmente durante meses después [21].

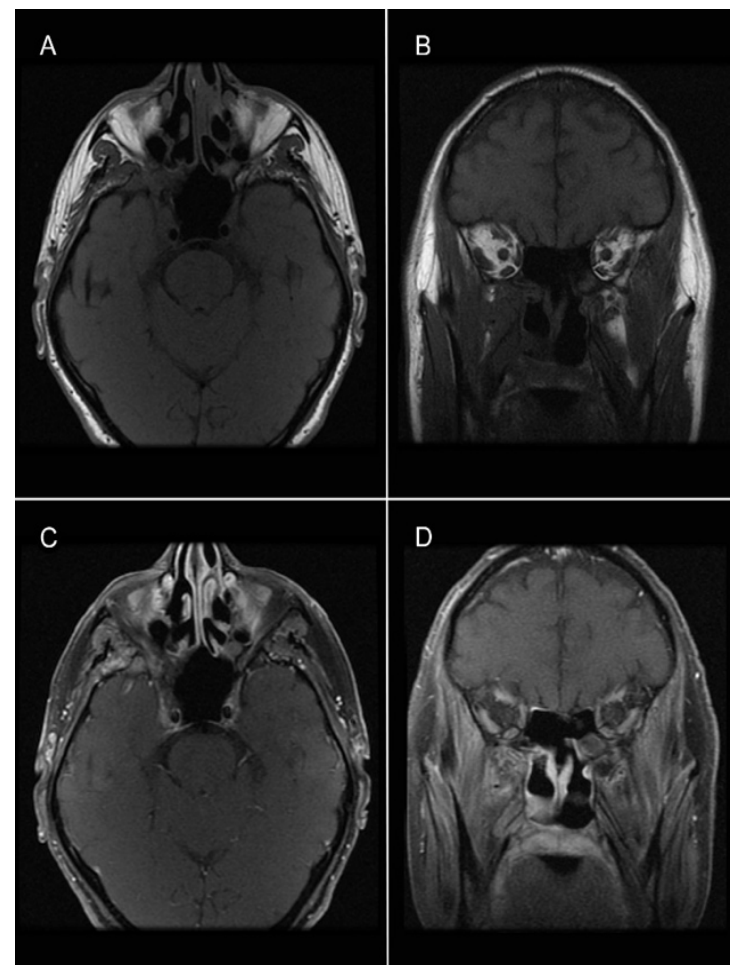

Figura 13. RM de senos paranasales. Estudio postratamiento del carcinoma linfoepitelioide en seno esfenoidal expuesto en la figura 11. (A) Secuencia T1 en el plano axial. (B) Secuencia T1 en el plano coronal. (C) Secuencia T1 saturación grasa tras la administración de contraste en el plano axial. (D) Secuencia T1 saturación grasa tras la administración de contraste en el plano coronal. Se aprecian cambios post-cirugía en seno esfenoidal y fosas nasales, realce de la mucosa y discreto realce de los músculos pterigoideo medial y lateral, músculo mastero y temporal derechos sugestivos de cambios posradioterapia. 

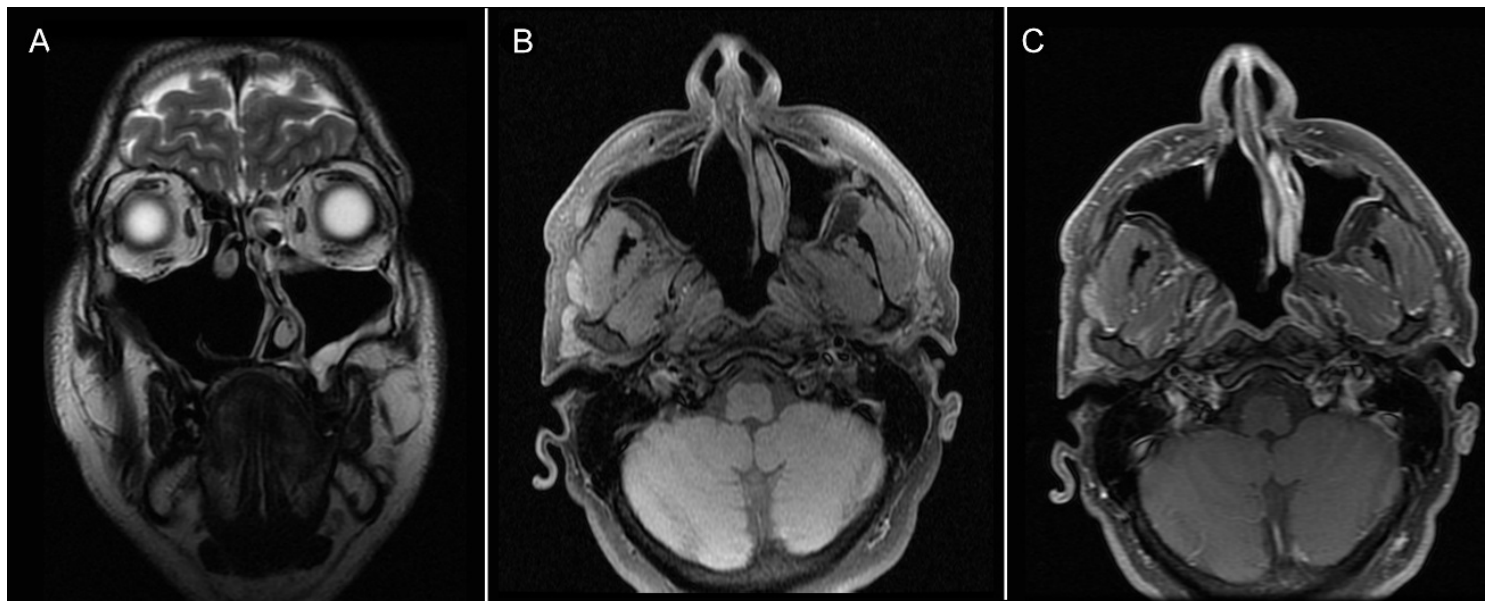

Figura 14. RM de senos paranasales. Estudio postratamiento del angiofibroma expuesto en la figura 12. (A) Secuencia T2 en el plano coronal. (B) Secuencia T1 saturación grasa en el plano axial. (C) Secuencia T1 saturación grasa tras la administración de contraste en el plano axial. Se aprecian cambios post-cirugía con ausencia de la pared medial del seno maxilar derecho
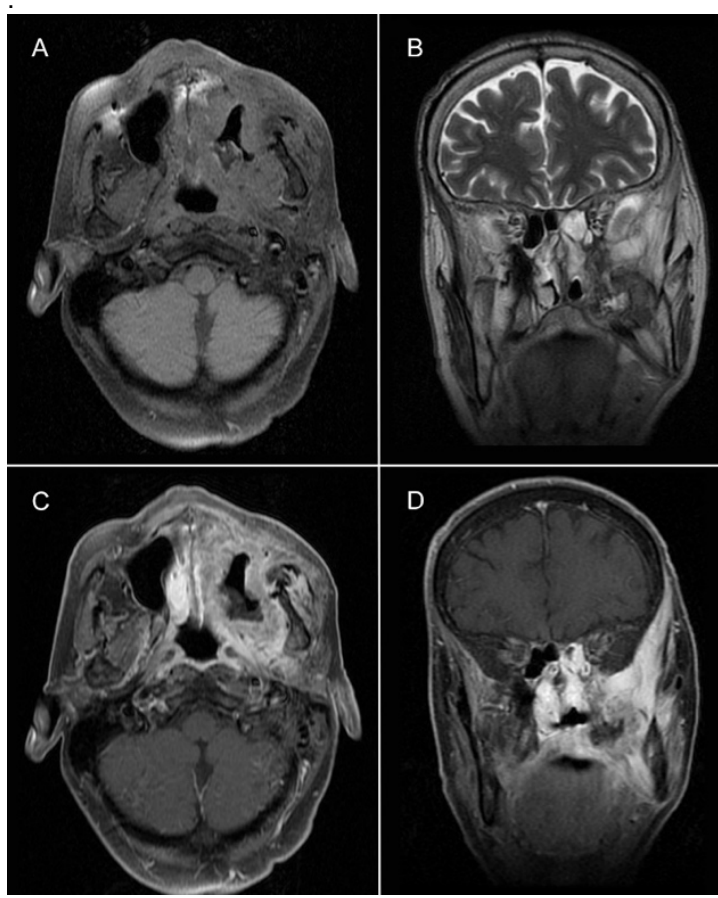

Figura 15. RM de senos paranasales. Estudio postratamiento de carcinoma neuroendocrino de seno maxilar. (A) Secuencia T1 saturación grasa en el plano axial. (B) Secuencia T2 en el plano coronal. (C) Secuencia T1 saturación grasa tras la administración de contraste en el plano axial. (D) Secuencia T1 saturación grasa tras la administración de contraste en el plano coronal. Se observa recidiva tumoral apreciando un marcado engrosamiento de la mucosa del seno maxilar izquierdo, que aumentó con respecto al anterior control, con intenso realce tras la administración de contraste y con infiltración de la musculatura pterigoidea ipsilateral.
Otros cambios apreciables en pruebas de imagen tras tratamiento adyuvante.

- La radioterapia adyuvante es frecuente en el caso de tumores agresivos o con márgenes mal definidos.

- La neuritis óptica se produce con mayor frecuencia después de la radioterapia de lesiones en las celdillas etmoidales o el seno esfenoidal, se identifica una hiperintensidad en secuencias T2 del nervio óptico o el quiasma [21].

La radionecrosis del SNC se produce normalmente en los lóbulos temporales, objetivando edema de la sustancia blanca y desmielinización previa a la necrosis, esta última caracterizada por un realce puntiforme, giriforme o serpiginoso. Cuando las alteraciones del parénquima cerebral son adyacentes al sitio de la neoplasia tratada, el diagnóstico diferencial entre cambios posradioterapia o recidiva puede resultar difícil [21] (Figura 15). La radionecrosis ósea puede afectar a cualquier hueso radiado, pero la incidencia más alta se produce en la mandíbula, porque habitualmente se incluye en el campo radiado de las neoplasias maxilares. Los cambios precoces incluyen edema difuso de la médula ósea (hiperintensidad en T2 e hipointensidad en T1) y realce. La osteonecrosis propiamente dicha se produce más tarde y se visualiza como áreas de hueso necrótico avascular rodeado de un realce en anillo o borde esclerótico [21]. 


\section{CONCLUSIONES}

Si bien la RM está por detrás de la TC en cuanto opciones de diagnóstico por imagen en el estudio de la patología nasosinusal, resulta especialmente útil para la valoración de patología tumoral dada su capacidad para distinguir entre diferentes tejidos y facilitar de esta manera el diagnóstico de extensión local del tumor. Además, la RM suele ser la técnica de elección para la valoración postratamiento.

\section{BIBLIOGRAFÍA}

1. Huang BY, Senior BA, Castillo $M$. Current Trends in Sinonasal Imaging. Neuroimaging clinics of North America. 2015;25(4):507-25.

2. Som PM, Shapiro MD, Biller HF, Sasaki C, Lawson W. Sinonasal tumors and inflammatory tissues: differentiation with MR imaging. Radiology. 1988;167(3):803-8.

3. Vaid S, Vaid N. Normal Anatomy and Anatomic Variants of the Paranasal Sinuses on Computed Tomography. Neuroimaging clinics of North America. 2015;25(4):527-48.

4. Connor SE. The Skull Base in the Evaluation of Sinonasal Disease: Role of Computed Tomography and MR Imaging. Neuroimaging clinics of North America. 2015;25(4):619-51.

5. Algin O, Turkbey $B$. Intrathecal gadoliniumenhanced MR cisternography: a comprehensive review. AJNR American journal of neuroradiology. 2013;34(1):14-22.

6. Sasaki M, Eida S, Sumi M, Nakamura T. Apparent diffusion coefficient mapping for sinonasal diseases: differentiation of benign and malignant lesions. AJNR American journal of neuroradiology. 2011;32(6):1100-6.

7. Sasaki M, Sumi M, Eida S, Ichikawa Y, Sumi $\mathrm{T}$, Yamada T, et al. Multiparametric MR imaging of sinonasal diseases: time-signal intensity curve- and apparent diffusion coefficient-based differentiation between benign and malignant lesions. AJNR American journal of neuroradiology. 2011;32(11):2154-9.
8. Cornelius RS, Martin J, Wippold FJ, 2nd, Aiken $\mathrm{AH}$, Angtuaco EJ, Berger $\mathrm{KL}$, et al. ACR appropriateness criteria sinonasal disease. Journal of the American College of Radiology : JACR. 2013;10(4):241-6.

9. Yousem DM. Imaging of sinonasal inflammatory disease. Radiology. 1993;188(2):303-14.

10. Joshi VM, Sansi R. Imaging in Sinonasal Inflammatory Disease. Neuroimaging clinics of North America. 2015;25(4):549-68.

11. Madani G, Beale TJ. Sinonasal inflammatory disease. Seminars in ultrasound, CT, and MR. 2009;30(1):17-24.

12. Rak KM, Newell JD, 2nd, Yakes WF, Damiano MA, Luethke JM. Paranasal sinuses on MR images of the brain: significance of mucosal thickening. AJR American journal of roentgenology. 1991;156(2):381-4.

13. Yoon JH, Na DG, Byun HS, Koh YH, Chung SK, Dong HJ. Calcification in chronic maxillary sinusitis: comparison of CT findings with histopathologic results. AJNR American journal of neuroradiology. 1999;20(4):571-4.

14. deShazo RD, O'Brien M, Chapin K, SotoAguilar M, Gardner L, Swain R. A new classification and diagnostic criteria for invasive fungal sinusitis. Archives of otolaryngology--head \& neck surgery. 1997;123(11):1181-8.

15. Chakrabarti A, Denning DW, Ferguson BJ, Ponikau J, Buzina W, Kita $\mathrm{H}$, et al. Fungal rhinosinusitis: a categorization and definitional schema addressing current controversies. The Laryngoscope. 2009;119(9):1809-18.

16. Raz E, Win W, Hagiwara M, Lui YW, Cohen B, Fatterpekar GM. Fungal Sinusitis. Neuroimaging clinics of North America. 2015;25(4):569-76.

17. Chung SK, Chang BC, Dhong HJ. Surgical, radiologic, and histologic findings of the antrochoanal polyp. American journal of rhinology. 2002;16(2):71-6.

18. Ozcan M, Ozlugedik S, Ikinciogullari A. Simultaneous antrochoanal and sphenochoanal polyps: a rare clinical entity. The Journal of laryngology and otology. 2005;119(2):152-4. 
19. Sen S, Chandra A, Mukhopadhyay S, Ghosh $P$. Imaging Approach to Sinonasal Neoplasms. Neuroimaging clinics of North America. 2015;25(4):577-93.

20. Sen S, Chandra A, Mukhopadhyay S, Ghosh P. Sinonasal Tumors: Computed Tomography and MR Imaging Features. Neuroimaging clinics of North America. 2015;25(4):595-618.

21. Maroldi R, Ravanelli M, Farina D, Facchetti L, Bertagna F, Lombardi D, et al. Post-treatment Evaluation of Paranasal Sinuses After Treatment of Sinonasal Neoplasms. Neuroimaging clinics of North America. 2015;25(4):667-85.

22. Loevner LA, Sonners Al. Imaging of neoplasms of the paranasal sinuses. Neuroimaging clinics of North America. 2004;14(4):625-46.

23. Tufano RP, Mokadam NA, Montone KT, Weinstein GS, Chalian AA, Wolf PF, et al. Malignant tumors of the nose and paranasal sinuses: hospital of the University of Pennsylvania experience 1990-1997. American journal of rhinology. 1999;13(2):117-23.

24. Ward BE, Fechner RE, Mills SE. Carcinoma arising in oncocytic Schneiderian papilloma. The American journal of surgical pathology. 1990;14(4):364-9.
25. Wang X, Zhang Z, Chen X, Li J, Xian J. Value of magnetic resonance imaging including dynamic contrast-enhanced magnetic resonance imaging in differentiation between inverted papilloma and malignant tumors in the nasal cavity. Chinese medical journal. 2014;127(9):1696-701.

26. Carrillo JF, Albores O, Ramirez-Ortega MC, Aiello-Crocifoglio V, Onate-Ocana LF. An audit of nasopharyngeal fibromas. European journal of surgical oncology : the journal of the European Society of Surgical Oncology and the British Association of Surgical Oncology. 2007;33(5):655-61.

27. Erdogan N, Demir U, Songu M, Ozenler NK, Uluc E, Dirim B. A prospective study of paranasal sinus osteomas in 1,889 cases: changing patterns of localization. The Laryngoscope. 2009;119(12):2355-9.

28. MacDonald-Jankowski DS. Fibro-osseous lesions of the face and jaws. Clinical radiology. 2004;59(1):11-25.

29. Scholl RJ, Kellett HM, Neumann DP, Lurie AG. Cysts and cystic lesions of the mandible: clinical and radiologic-histopathologic review. Radiographics : a review publication of the Radiological Society of North America, Inc. 1999;19(5):1107-24

30. Maroldi R, Farina D, Battaglia G, Maculotti P, Nicolai P, Chiesa A. MR of malignant nasosinusal neoplasms. Frequently asked questions. European journal of radiology. 1997;24(3):181-90. 